\title{
Microsatellite markers in Aquaculture: Application in Fish population genetics
}

\author{
Mojekwu, T.O ${ }^{1}$ and Anumudu,C.I ${ }^{2}$ \\ 1. Department of Aquaculture/Biotechnology unit, Nigerian Institute for Oceanography and Marine Research. \\ 2. Department of Zoology, University of Ibadan.
}

\begin{abstract}
Microsatellites or Simple Sequence Repeats (SSRs) represent an abundant source of genetic markers which are highly abundant and dispersed evenly throughout eukaryotic genomes. They have become the markers of choice for a wide range of applications in population genetic, conservation and evolutionary biology. Microsatellites represent ideal molecular markers because they have multiple alleles which are highly polymorphic among individuals. Polymorphism is achieved by having variable numbers of tandem repeat motifs resulting in size variation which can then be visualized by PCR with pairs of locus-specific flanking primers, followed by electrophoresis of the amplification product. Microsatellite motifs occurs once every $10 \mathrm{~kb}$ in fishes. They are inherited in a co-dominant fashion, and are fast and easy to assay. They are co-dominant in nature with high levels of polymorphism and can reproduce very well. Hence, giving better information than the dominant marker. This makes them a choice maker for estimating population structure and genetic diversity.
\end{abstract}

Keywords: Microsatellites, markers, fish, population, genetics

\section{Introduction}

Molecular genetic markers are powerful tools to detect genetic uniqueness of individuals, populations or species (Doveri et al., 2008). Modern sequence based marker systems for genetic analysis such as Single Nucleotide Polymorphisms (SNPs) and Simple Sequence Repeats (SSRs) are now predominantly used (Duran et al. 2009).

However, Microsatellites have become the marker of choice for application in fish population genetic studies (Beckmann and Soller, 1990). They have multiple alleles which are highly polymorphic among individuals. The polymorphism obtained with microsatellite markers has provided powerful information to be considered in the management of fish stocks (Alam and Islam, 2005), population analysis and biodiversity conservation (Romana-Eguia et al., 2004). Simple Sequence Repeat (SSR) markers are preferable because they are potentially co-dominant and highly polymorphic. In addition; microsatellites have a wide distribution in the genome and can be efficiently identified, which is essential in studies about genetic variability of populations (Boris et al., 2011).

High cost of developing species-specific markers has been the main challenge of microsatellite markers in the past is the (Castoe et al., 2010). Now, this has been alleviated with the advent of Next-generation sequencing, which allows the detection and characterization of SSR loci easily achievable with simple bioinformatics (Abdelkrin et al., 2009).

Recently, molecular markers have been commonly used for population studies (Al-Atiyat et al., 2012). Microsatellites have been used to study the genetic diversity of farmed and wild population's fishes (Norris et al., 1999; Boris et al, 2011).

In Nigeria, molecular marker based on PCR techniques has been used to determine population structure, and genetic diversity of fish (Ahmad et al., 2012; Mojekwu et al., 2012). Though there is little information in this area.

Therefore, this write up x-rays the applications and relevance of SSR markers to fish population genetics in aquaculture.

\section{Population Genetics}

Population genetics is the study of genetic variation among species, individuals and populations; fundamentally, it shows that distribution of genetic variability is affected by evolutionary forces of mutation, migration, selection, and random genetic drift (Hansen, 2003).

Assessing genetic diversity in aquaculture stocks or wild fish populations is crucial for effective management, interpretation, and understanding and of fish populations or stocks.

Many characteristics and methods have been used to analyze stock structure in fish populations; they include ecological, tagging, parasite distribution, physiological and behavioural traits, morphometrics and meristics, calcified structures, cytogenetics, immunogenetics and blood pigments (Samaradivakara et al., 2012). 
Unfortunately, environmental variables often affect the relationship between genes and their phenotypic expression significantly.

Thus, the population geneticists mainly focused on Mendelian traits in species widely used in laboratory studies or on available pure breeds of few species (Hallerman, 2003).

The development of DNA amplification using the PCR (Polymerase Chain Reaction) technique opened up the possibility of examining genetic changes in fish populations over the past years (Ferguson et al., 1995). Today many molecular methods are available for studying various aspects of wild populations, captive brood stocks and interactions between wild and cultured stocks of fish and other aquatic species (Yudha et al., 2012). The choice of markers for particular method is not straightforward and mostly depends on the experience of the investigators, laboratory facilities and available fund. Thus, there is a need for occasional reviews of the developments in techniques, applications and interpretations of the data gathered.

\section{Microsatellite}

Microsatellites are highly abundant in various eukaryotic genomes including all aquaculture species studied to date. In most of the vertebrate genomes, microsatellites make up a few percent of the genomes in terms of the involved base pairs, depending on the compactness of the genomes (Zhan et al., 2009).

In fish, one microsatellite was found every $1.87 \mathrm{~kb}$ of DNA. For comparison, in the human genome, one microsatellite was found every $6 \mathrm{~kb}$ of DNA (Beckmann and Weber 1992). It is reasonable to predict that in most aquaculture fish species, one microsatellite should exist every $10 \mathrm{~kb}$ or less of the genomic sequences, on average (Wright, 1993; Duran et al., 2009).

Their high polymorphism, and PCR based analysis has made them one of the most popular genetic markers ((Duran et al. 2009; Boris et al., 2011).

Some microsatellite loci have very high numbers of alleles per locus $(>20)$, making them very useful for applications such as parent-offspring identification in mixed populations, while others have lower numbers of alleles and may be more suited for population genetics and phylogeny (Al-Atiyat et al.,2012). Primers developed for one species will often cross-amplify microsatellite loci in closely related species (Boris et al, 2011). Genotyping of microsatellite markers is usually straightforward (Castoe et al., 2010).

However, its disadvantage include the requirement for existing molecular genetic information, the large amount of up front work for microsatellite development, and the tedious and labor intensive nature of microsatellite primer design, testing, optimization of PCR conditions and cost (Telles et al., 2010).

\section{Applications of Microsatellite Markers in fish population}

Microsatellite markers are ideal for many types of applications in aquaculture. They give crucial information in aquaculture fish population, such as: (i) identification of Genetic variability between and within stocks; (ii) monitoring Genetic changes in stocks; (iii) parentage and pedigree analysis in selective breeding ;(iv) Genomic mapping and detection of quantitative trait loci (QTL) (Fjalestad et al., 2003;Subasinghe et al., 2003; Chistiakov et al.,2005).

Several papers has reviewed the use of Microsatellite markers in aquaculture, in particular their integration into breeding programmes (e.g.Fjalestad et al., 2003; Taniguchi, 2003; Cross et al., 2004; Boris et al 2011; Al-Atiyat et al.,2012).

\section{Identification of Genetic Variability between and within Fish Stocks}

Molecular markers can be useful tools in stock identification and monitoring potential changes in broodstock, called DNA fingerprinting (Fjalestad et al., 2003; Ahmad et al., 2012; Mojekwu et al., 2012). Almost all major molecular markers from allozymes to microsatellite have been used in determination of between and within genetic variations in hatchery stocks (Sekino et al., 2002; Ramos- Paredes and GrijalvaChon, 2003; Samy-Yehya et al., 2012).

Studies have shown loss of genetic variation in hatchery stocks (e.g. in salmonids) as a result of different factors including a low effective number of parents, domestication selection or the mating design ( Samaradivakara et al., 2012). Sekino et al. (2002) assessed genetic divergence within and between hatchery, and wild populations of Japanese flounder (Paralichthys olivaceus) by means of microsatellite and mtDNA sequencing analysis. Desvignes et al. (2001) studied the genetic variability of French and Czech strains of hatchery stocks of common carp (Cyprinus carpio) using allozymes and microsatellites. They detected a more pronounced discrimination between the strains of the two countries by the microsatellite markers. Bartfai et al.

(2003) analyzed the whole broodstock of two Hungarian common carp farms (80 and 196 individuals) by using RAPD assay and microsatellite analysis. Microsatellite analysis was more informative than RAPD assay. Microsatellites are the assay of choice for the discrimination of culture stocks (Duran et al., 2009; Boris et al., 2011). 


\section{Monitoring Genetic Changes in stocks}

Microsatellite assays have been very successful in detecting the genetic impact of culture (Zhan et al., 2009). The higher sensitivity Microsatellite to phenomena such as genetic drift and founder effect make this marker ideal for monitoring the consequences of founding and propagation in aquaculture than of mtDNA and allozyme (Duran et al., 2009).

Microsatellite markers have been used for minimizing inbreeding in rainbow trout (Fishback et al., 1999). Analysis of the F1 generation of a Greek gilthead sea bream broodstock revealed a $15 \%$ reduction in the number of alleles and a homozygosity increase of 1.5\% (Magoulas, 1998).

Thus, SSR markers have important applications in monitoring inbreeding depression. For example, microsatellite markers can be used to locate the specific chromosomal regions responsible for inbreeding depression. This would be most feasible with cultured species where parents and their progeny can be managed and traced within a closed system. It will be possible to use mapped genetic markers to trace the inheritance of specific chromosomal arms in progeny (Morelli, 2007). The polymorphism obtained with microsatellite markers have provided strong information utilized in the management of fish stocks (Alam and Islam, 2005).

\section{Parentage and Pedigree Analysis in Selective Breeding}

Selection programmes uses both information on the candidates for selection and their relatives in order to increase the precision of selection and hence selection responses.

One of the applications of Microsatellite markers in brood stock management is in the assessing of the contribution of possible parents in a mass spawning. Typically limited numbers of broods are used in spawning and some putative parents apparently fail to spawn. In this case SSR and other genetic markers, becomes useful in quantifying the relative success of the potential parents. Parentage can be determined using minisatellite or microsatellite markers after spawning (Moran et al., 1996; Thompson et al., 1998).

One of the most important hindrances to applying effective selective breeding programmes for fish is that newborn individuals are too small to be tagged physically.

Thus, selective programmes making use of family information have needed to keep families separated until the fish are large enough to be individually tagged. This is costly, limits the number of families available for selection and can induce environmental effects common to the members of the same family (Doyle and Herbinger, 1994).

This problem can be resolved by applying Microsatellite and other DNA-based genetic markers. Consequently, more families can be kept in the breeding stock without the need for using separate tanks at early ages. These markers have been used to assess family/parentage identification in many species and can be used to discriminate fish in mixed family groups (e.g. Herbinger et al., 1995; Fjalestad et al., 2003; Cross et al., 2004; Duran et al., 2009; Boris et al., 2011; Al-Atiyat et al.,2012).

A breeding programme can be initiated with a previously unselected farm raised strain by using a method, termed walk-back selection (Doyle and Herbinger, 1994). In general, this will involve the physical tagging and biopsy of individuals when they are large enough to be marked, with microsatellite analysis based on the biopsy used to assign individuals to family.

Several studies have empirically used microsatellite loci to successfully reconstruct pedigrees in fish populations with families mixed from hatching (Norris et al. 2000;Morelli 2007;Zhan et al., 2009; Olivatti et al.,2011).

Villanueva, developed deterministic predictions for the power of microsatellites for parental assignment and compared with stochastic simulation results. Their results showed that the four loci that are more informative are enough to assign the offspring to the correct pair up to $99 \%$ with 100 crosses that involves 100 males and females respectively. Doyle et al. (1994) used them to discriminate family groups of cod (Gadus morhua). In these cases, offspring assignment was to known parental types.

However, with sufficient levels of variability, family or parental discrimination may also be achievable in the absence of parental information (Norris et al., 2000). However, microsatellites appears more popular because of their potential for high variability even among individuals of the same strain (Liu and Cordes 2004).

\section{QTLs of aquatic organisms}

A high number of QTL research has been conducted for sex determination and sex linkage in fish using microsatellites because of the great interest in producing monosex populations of certain species.

Sex linked inheritance in fish was first reported by Aida (1921) in medaka. Waldbieser et al. (2001) examined 293 polymorphic microsatellite loci in channel catfish, and seven of these loci were closely linked to the sex-determining chromosome region. Oreochromis QTLs for sex and colour have been mapped (Kocher et al., 2002). 
Ozaki et al. (2001) used 51 microsatellite markers to identify several chromosome regions containing putative QTL genes that affect resistance to infectious pancreatic necrosis (IPN) in rainbow trout. Tanck et al. (2001) utilized 11 microsatellites and found that they were correlated with stress-related plasma cortisol levels and basal plasma glucose levels in common carp.

QTLs for fitness traits and survival have been identified in fish and shellfish. A microsatellite accounted for $7.5 \%$ of the variance in thermal tolerance in unselected populations of rainbow trout (Perry et al., 2001).

Table of some examples of linkage maps constructed with microsatellite markers in aquaculture species.

\begin{tabular}{|l|l|l|}
\hline Species & Common name & References \\
\hline Salmo trutta & Brown trout & Gharbi et al., 2006 \\
\hline Dicentrarchus labrax & European sea bass & Chistiakov et al., 2005 \\
\hline Oreochromis spp. & Tilapia & Lee et al., 2005 \\
\hline Plecoglossus altivelis Xiphophorus & Ayu & Watanabe et al. 2004, Walter et al.,2004 \\
\hline Salvelinus alpinus & Arctic char & Woram et al., 2004 \\
\hline Salmo salar & Atlantic salmon & Gilbey et al., 2004, Moen et al., 2004 \\
\hline Oncorhynchus mykiss & Rainbow trout & Sakamoto et al., 2000, Nichols et al., 2003 \\
\hline Ictalurus punctatus & Channel catfish & Waldbieser et al., 2001 \\
\hline Danio rerio & Zebrafish & Shimoda et al.,1999 \\
\hline Crassostrea gigas & Pacific oyster & Hubert and Hedgecock 2004 \\
\hline Crassostrea virginica & Eastern oyster & Yu and Guo 2003 \\
\hline Seriola quinqueradiata and Seriola lalandi & Yellowtails & Ohara et al. ,2005 \\
\hline Cyprinus carpio & Common carp & Sun and Liang 2004 \\
\hline Paralichthys olivaceus & Japanese flounder & Coimbra et al., 2005 \\
\hline
\end{tabular}

Source: Zhanjiang, J. L (2007).

Microsatellite application to fish Population genetics in Nigeria.

The applications of molecular-based knowledge in fish genetics and stock management have been confined to developed and some Asian developing countries.

Several papers has reviewed the use of microsatellite markers in aquaculture and fisheries, (e.g Fegurson et al., 1995;Davis and Hetzel, 2000;Fjalestad et al., 2003; Taniguchi, 2003; Cross et al., 2004; Alam and Islam 2005;Boris et al.,2011; Al-atiyat et al., 2012; Yudha et al., 2012).

In Nigeria, quite a number of published work exist on molecular markers in fish characterization using RAPD markers (Ahmad et al., 2012; Mojekwu et al., 2012; Megbowon and Bombata, 2013; Mojekwu et al., 2013).

However, there are little or no publications and information to the best of my search on the use of microsatellite markers to study fish population in Nigeria.

Though Microsatellite markers have been applied in Nigeria to study population and genetic diversities in livestock; chicken (Olowofeso et al., 2005), Insects; malaria mosquitoes and plants (Fatokun, et al., 2008; Ogunkanmi et al., 2010).

\section{Conclusion}

Microsatellites have enabled the assessment of genetic variations at much smaller scales than has been possible with other markers (Sunnucks, 2000; Boris et al., 2011).

The polymorphism obtained with microsatellite markers has given useful and detailed information in fish stocks management (Alam and Islam, 2005), biodiversity conservation and population analysis (RomanaEguia et al., 2004). They are optimal for mapping "causal" genes, whether these are responsible for single or multifactorial traits (QTLs). They are also the best markers for determining parenthood in mass spawning and/or rearing even for evolutionarily related genera ( Zhan et al., 2009), tracing escapes from cultured to wild populations and estimating coefficients of kinship among individuals drawn from a population (Hansen et al., 2001).

Many studies have successfully demonstrated heterologous amplification of a target specie with SSR primer (Barbosa et al., 2006; Hatanaka et al., 2006, Morelli et al., 2007), thereby lowering the costs of future projects.

Nevertheless, their major drawback remains the high cost and labour intensity involved in the development of primers (Telles et al., 2010). Another disadvantage is the existence of null alleles that is alleles that do not amplify in PCR reactions (O'Really and Wright, 1995). 


\section{References}

[1]. Abdelkrim,J.,Robertson,B.C.,Stanton,J.A and Gemmell,N.J (2009).Fast, cost-effective development of species - specific microsatellite markers by genomic sequencing. Biotechniques , 46:185-192.

[2]. Ahmad J.N., Azizah, M.N., Adikwu, I.A., Istifanus, W. A.,Abalis,G.E and Muchlisin,Z.A (2012). Diversity and distribution of fishes of Gaji River, Bauchi state Nigeria. Advances in Environmental sciences-International journal of the bioflux society vol 4, issue 2. Pp.50 -54.

[3]. Aida, T. (1921) On the inheritance of color in a freshwater fish, Aplocheilus latipes, Temmick and Schlegel. Genetics 6, 554-573.

[4]. Alam S and Islam S (2005). Population genetic structure of Catla catla (Hamilton) revealed by microsatellite DNA markers. Aquaculture 246: 151-160.

[5]. Al-Atiyat,R.M., Tabbaa, M.J., Salameh,N.M., Tarawneh, K.A.,Al-shamyla .L and Al- Tamimie, H.J (2012).Analysis of genetic fat tailed sheep in southern region of Jordan.Asian J.Anim. Vet.Adv.,7:376 -389.

[6]. Bartfai, R., Egedi, S., Yue, G.H., Kovacs, B., Urbanyi, B., Tamas, G., Horvath, L. and Orban, L (2003). Genetic analysis of two common carp broodstocks by RAPD and microsatellite markers. Aquaculture, 219: 157-167.

[7]. Barbosa ACDR, Corrêa TC, Galzerani F, Galetti-Júnior PM. (2006). Thirteen polymorphic microsatellite loci in the Neotropical fish Prochilodus argenteus (Characiformes, Prochilodontidae). Mol. Ecol. Notes 6: 936-938.

[8]. Beckmann, J.S and Soller, M (1990). Toward a unified approach to genetic mapping of eukaryotes based on sequence tagged microsatellite sites. Bio/Technology 8, 930- 932

[9]. Beckman, J.S and Weber, J.L (1992). Survey of human and rat microsatellites. Genomics, 12, pp. 627-631.

[10]. Boris Brinez, Xenia Caraballo O, Marcel Salazar V (2011). Genetic diversity of six populations of red hybrid tilapia, using Microsatellite genetic Markers. Rev.MVZ Cordoba 16 (2): 2491-2498.

[11]. Castoe,T.A.,Poole,A.W.,Gu, W.,De Koning,A.P and Daza,J.M (2010). Rapid identification of thousands of copperhead snake (Agkistrodon contortrix) microsatellite loci from modest amounts of 454 shotgun genome sequence.Mol Ecol Resour 10:341-347.

[12]. Chistiakov DA, B Hellemans, CS Haley, AS Law, CS Tsigenopoulos, G Kotoulas, D Bertotto, A Libertini, and FA Volckaert (2005). A microsatellite linkage map of the European sea bass Dicentrarchus labrax L. Genetics, 170, pp. 1821-1826.

[13]. Cross, T., Dillane, E. and Galvin, P (2004). Which molecular markers should be chosen for different specific applications in fisheries and aquaculture http://www.ucc.ie/ucc/research/adc/molmark/index. html. Last accessed on 23 March 2004.

[14]. Davis, G.P. and Hetzel, D.J.S. (2000) Integrating molecular genetic technology with traditional approaches for genetic improvement in aquaculture species. Aquaculture Research 31, 3-10.

[15]. Desvignes, J.F., Laroche, J., Durand, J.D. and Bouvet, Y (2001). Genetic variability in reared stocks of common carp (Cyprinus carpio L.) based on allozymes and microsatellites. Aquaculture, 194: 291-301.

[16]. Doveri S, Lee D, Maheswaran M, Powell W (2008). Molecular markers: History, features and applications. In Principles and Practices of Plant Genomics, Volume 1, C.K.a.A.G. Abbott, ed. (Enfield, USA: Science Publishers), pp. $23-68$.

[17]. Doyle, R.W. and Herbinger, C.M (1994). The use of DNA fingerprinting for high intensity, within-family selection in fish breeding, In: Proceedings of the $5^{\text {th }}$ World Congress on Genetics Applied to Livestock Production, Guelph, Canada. 19: 23-27.

[18]. Doyle, R.W., Perez-Enriquez, R., Takagi, M. and Taniguchi, N. (1994) Selective recovery of founder genetic diversity in aquacultural broodstocks and captive endangered fish populations. Genetica 111, 291-304.

[19]. Duran, C., Nikki,A.,David,E and Jacqueline B (2009).Molecular Genetic Markers: Discovery, Applications,Data stoarage and visualization.Current Bionformatics 11,37 -41.

[20]. Fatokun,C.A.,Ogunkanmi, A.,Ogundipe,O.T and Ng, N.Q (2008).Genetic diversity in wild relatives of cowpea (Vigna unguiculata) as revealed by simple sequence repeats (SSR) markers.Journal of Food,Agriculture \& Environment Vol.6 (3\&4):263 -268.

[21]. Ferguson, A., Taggart, J.B., Prodohl, P.A., McMeel, O.,Thompson, C., Stone, C., McGinnity, P. and Hynes, R.A (1995). The application of molecular markers to the study and conservation of fish populations, with special reference to Salmo.Journal of Fish Biology,47:103-126.

[22]. Ferguson, M.M. and Danzmann, R.G (1998). Role of genetic markers in fisheries and aquaculture: useful tools orstamp collecting? Can. J. Fish. Aquat. Sci., 55:1553-1563.

[23]. Fishback, A.G., Danzmann, R.G., Sakamoto T. and Ferguson, M.M (1999). Optimization of semiautomated microsatellite multiplex PCR systems for rainbow trout (Oncorhynchus mykiss). Aquaculture,172:247-254.

[24]. Fjalestad, K.T., Moen, T. and Gomez-Raya, L ( 2003). Prospects for geentic technology in salmon breeding programees. Aquaculture Research, 34: 397-406.

[25]. Hallerman, E.M (2003). Population genetics: principles and applications for fisheries scientists. American Fisheries Society, Bethesda, Maryland: $458 \mathrm{pp}$.

[26]. Hansen, M.M (2003). Application of molecular markers in population and conservation genetics, with special emphasis on fishes. DSc Thesis, Faculty of Natural Sciences, University of Aarhus, 68 pp.

[27]. Hansen, M.M., Ruzzante, D.E., Nielsen, E.E. and Mensberg, K.L.D. (2001) Brown trout (Salmo trutta) stocking impact assessment using microsatellite DNA markers. Ecological Applications 11, 148-160.

[28]. Hatanaka T, Henrique-Silva F and Galetti PM Jr (2006). Population substructuring in a migratory freshwater fish Prochilodus argenteus (Characiformes, Prochilodontidae) from the Sao Francisco River. Genetica 126: 153-159.

[29]. Herbinger, C.M., Doyle, R.W., Pitman, E.R., Paquet, D., Mesa, K.A., Morris, D.B., Wright, J.M. and Cook, D. (1995) DNA fingerprint-based analysis of paternal and maternal effects on offspring growth and survival in communally reared rainbow trout. Aquaculture 137, 245-256.

[30]. Kocher, T.D., Albertson, R.C., Carleton, K.L. and Streelman, J.T. (2002) The genetic basis of biodiversity: genomic studies of cichlid fishes. In: Shimizu, N., Aoki, T., Hirono, I. and Takashima, F. (eds) Aquatic Genomics: Steps Toward a Great Future. Springer-Verlag, New York, pp. 35-44.

[31]. Liu ZJ and JF Cordes (2004). DNA marker technologies and their applications in aquaculture genetics. Aquaculture, 238 , pp. 1-37.

[32]. Magoulas, A (1998). Application of molecular markers to aquaculture and broodstock management with special emphasis on microsatellite DNA. Cahiers Options Mediterrannes, 34: 153- 168.

[33]. Megbowon I and Fashina-Bombata, H.A (2013). Molecular Characterization of an Unidentified Cichlid, Commonlly Called, 'Wesafu', Using RAPD Markers. IOSR Journal Of Environmental Science, Toxicology And Food Technology, 5 (2): 22 - 26

[34]. Mojekwu, T.O, Oguntade, O.R, Oketoki.T.O and Usman A.B (2012). Genetic variability of Tilapia in different water bodies using RAPD markers. Proceedings of the $25^{\text {th }}$ Annual Conference of the Biotechnology Society of Nigeria. Held at National Open University, Abuja. 26th $-31^{\text {st }}$ August, 2012.

[35]. Mojekwu, T.O, Oguntade, O.R, Oketoki,T.O Usman, A.B and Omidiji, O (2013).Molecular characterization of Tilapia in different water bodies using RAPD Markers. African Journal of Applied Biotechnology Research, 1(1):1-12. 
[36]. Moran, P., Pendas, A.M., Beall, E. and Garcsa-Vazquez, E (1996). Genetic assessment of the reproductive success of Atlantic salmon precocious parr by means of VNTR loci. Heredity, 77: 655-660.

[37]. Morelli KA, Revaldaves E, Oliveira C and Foresti F (2007). Isolation and characterization of eight microsatellite loci in Leporinus macrocephalus (Characiformes: Anostomidae) and cross-species amplification. Mol. Ecol. Notes 7: 32-34.

[38]. Norris, A.T., Bradley, D.G. and Cunningham, E.P. (1999) Microsatellite genetic variation between and within farmed and wild Atlantic salmon (Salmo salar) populations. Aquaculture 180, 247-264.

[39]. Norris, A.T., Bradley, D.G. and Cunningham, E.P. (2000).Parentage and relatedness determination in farmed Atlantic salmon (Salmo salar) using microsatellite markers. Mol Ecol, 11, pp. 155-165.

[40]. O'Connell, M. and Wright, J.M (1997). Microsatellite DNA in fishes. Reviews in Fish Biology and Fisheries, 7: 331 -363.

[41]. Ogunkanmi, L.A.,Ogundipe, O.T and Fatokun, C.A (2010). Comparative analysis of genetic diversity and genetic relatedness between cultivated and wild cowpea [Vigna unguiculata (L.) Walp.] based on agronomic traits and microsatellite markers. World Cowpea Conference Abstracts USA

[42]. Olivatti A.M, T.A. Boni, N.J. Silva-Júnior, L.V. Resende, F.O. Gouveia and M.P.C. Telles (2011). Heterologous amplification and characterization of microsatellite markers in the Neotropical fish Leporinus friderici Genet. Mol. Res. 10 (3): $1403-1408$.

[43]. Olowofeso,O.,Wang,J.Y.,Dai,D.J.,Yang,Y.,Mekki, D.M and Musa,H.H (2005).Measurement of genetic parameters within and between Haimen chicken populations using microsatellite markers.International Journal of Poultry Science,4 :143 -148.

[44]. O'Reilly, P. and Wright, J.M (1995). The evolving technology of DNA fingerprinting and its application to fisheries and aquaculture. J. Fish Biol., 47: 29-55

[45]. Ozaki, A., Sakamoto, T., Khoo, S., Nakamura, K., Coimbra, M.R., Akutsu, T. and Okamoto, N. (2001) Quantitative trait loci (QTLs) associated with resistance/susceptibility to infectious pancreatic necrosis virus (IPNV) in rainbow trout (Oncorhynchus mykiss). Molecular Genetics and Genomics 265, 23-31.

[46]. Perry, G.M.L., Danzmann, R.G., Ferguson, M.M. and Gibson, J.P. (2001) Quantitative trait loci for upper thermal tolerance in outbred strains of rainbow trout (Oncorhynchus mykiss). Heredity 86, 333-341.

[47]. Ramos-Paredes, J. and Grijalva-Chon, J.M (2003). Allozyme genetic analysis in hatchery strains and wild blue shrimp, Penaeus (Litopenaeus) stylirostris (Stimpson), from the Gulf of California. Aquaculture Research, 34: 221-234.

[48]. Romana-Eguia MRR, Ikeda M, Basiao ZU and Taniguchi N (2004). Genetic diversity in farmed Asian Nile and red hybrid tilapia stocks evaluated from microsatellite and mitochondrial DNA analysis. Aquaculture 236: 131-150.

[49]. Samy-Yehya ,E.,Mohammed Morsi, M.A.,Mohamed, E.S and Walid, N.E (2012).phylogenetc differentiation of wild and cultured Nile Tilapia (Oreochromis niloticus) populations based on phenotype and genotype analysis. African Journal of Agricultural Research vol. 7(19), pp.2946 -2954.

[50]. Samaradivakara,S.P.,Hirimuthugoda,N.Y.,Gunawaradana,R.H.,Illeperuma,R.J.,Fernandopulle N.D., De Silva A.D and Alexander, P.A (2012).Morphological variation of four Tilapia population in selected Reservoirs in Sri lanka.Tropical Agriculture Research vol. 23 (2) : $105-116$.

[51]. Sekino, M., Hara, M. and Taniguchi, N (2002). Genetic Diversity Within and Between Hatchery Strains of Japanese Flounder Paralichthys olivaceus Assessed by Means of Microsatellite and Mitochondrial DNA Sequencing Analysis. Aquaculture, 213: 101122.

[52]. Subasinghe, R.P., Curry, D., McGladdery, S.E. and Bartley, D (2003). Recent Technological Innovations in Aquaculture. In: Review of the State of World Aquaculture. FAO Fisheries Circular No.886, Rev. 2, Rome: 59-74.

[53]. Sunnucks, P (2000). Efficient genetic markers of population biology. Trends in Ecology and Evolution, 15: $199-203$.

[54]. Tanck, M.W.T., Palstra, A.P., Van De Weerd, M., Leffering, C.P., Van Der Poel, J.J., Bovenhuis, H. and Komen, J. (2001) Segregation of microsatellite alleles and residual heterozygosity at single loci in homozygous androgenetic common carp (Cyprinus carpio L.). Genome 44, 743-751.

[55]. Taniguchi, N (2003). Genetic factors in broodstock management for seed production. Reviews in Fish Biology and Fisheries, 13: $177-185$.

[56]. Telles MP, Resende LV, Brondani RP, Collevatti RG (2010). Isolation and characterization of microsatellite markers in the armored catfish Hypostomus gymnorhynchus (Loricariidae). Genet. Mol. Res. 9: 1770-1774.

[57]. Thompson, C.E., Poole, W.R., Matthews, M.A. and Ferguson, A (1998). Comparison, using minisatellite DNA profiling, of secondary male contribution in the fertilisation of wild and ranched Atlantic salmon (Salmo salar) ova. Can. J. Fish. Aquat. Sci., 55:2011- 2018 .

[58]. Waldbieser, G.C., Bosworth, B.G., Nonneman, D.J. and Wolters, W.R. (2001) A microsatellite-based genetic linkage map for channel catfish, Ictalurus punctatus. Genetics 158, 727-734.

[59]. Wright, J.M. (1993) .DNA fingerprinting in fishes. In: W.Hochachka, P. and Mommsen, T. Eds., Biochemistry and Molecular Biology of Fishes, Elsevier, Amsterdam, 58-91.

[60]. Yudha, T.A., Jan-Lung, C and Jin- chywan, G (2012).Genetic diversity of Indonesian Milkfish (Chanos Chanos) using Amplified Fragment Length Polymorphism (AFLP) analysis.African Journal of Biotechnology vol. 11 (13) pp.3055 -3060.

[61]. Zhan,A., Wang, Y.,Brown, B and Wang, H.P (2009).Isolation and characterization of novel microsatellite markers for yellow perch (Perca Flavescens).Int.J.Mol. Sci.10:18 -27.

[62]. Zhanjiang J. L (2007). Microsatellite Markers and Assessment of Marker Utility Aquaculture Genome Technologies ,Blackwell publishing 1 (5) 43-57. 